\title{
Developing a traumatic brain injury registry: lessons learned from difficulties
}

\author{
Amit Agrawal', M. Veera Prasad ${ }^{2}$, S. Satish Kumar ${ }^{3}$, B.V. \\ Subrahmanyan ${ }^{4}$, P.N. Harisha ${ }^{5}$, G. Malleswara Rao ${ }^{1}$ \\ ${ }^{1}$ Professor of Neurosurgery, Department of Neurosurgery, Narayna Medical College Hospital, \\ Chinthareddypalem, Nellore, Andhra Pradesh (India); ${ }^{2}$ Associate Professor: Department of \\ Hospital Administration, Narayna Medical College Hospital, Chinthareddypalem, Nellore, \\ Andhra Pradesh (India); ${ }^{3}$ Associate Professor of Emergency Medicine, Department of \\ Emergency Medicine, Narayana Medical College Hospital, Chinthareddypalem, Nellore, Andhra \\ Pradesh (India); ${ }^{4}$ Professor of Forensic Medicine, Department of Forensic Medicine, Narayana \\ Medical College Hospital, Chinthareddypalem, Nellore, Andhra Pradesh (India); ${ }^{5}$ Assistant \\ Professor of Neurosurgery, Department of Neurosurgery, Narayna Medical College Hospital, \\ Chinthareddypalem, Nellore, Andhra Pradesh (India)
}

\begin{abstract}
Aim: The aim of present article is to share our experiences and lessons learned from a pilot study which was conducted to collect data to serve as a model in establishing a multicenter registry on traumatic brain injury patients.

Methods: The present study was conducted from December 2013 to June 2014 in the Department of Neurosurgery and Department of Accident and Emergency Medicine. All patients with the diagnosis of traumatic brain injury (as per the criteria laid by International Classification of Disease injury codes ICD 10) were enrolled in the study. Variables were identified as per the international norms and the data points were selected which included demographic details, pre-hospital characteristics, clinical details in emergency room, injury details, course during hospital
\end{abstract}

stay, treatment and disposition. The data were categorized into master data, data related to pre-hospital events including pre-hospital care, data related to emergency room care offered in the emergency department, data related to hospital stay and patient course, outcome and follow up.

Results: A total of 231 patients were admitted with the diagnosis of traumatic brain injury. There were $79.1 \%$ male and $20.5 \%$ female patients. Mean age was 37.19 years ( $\mathrm{SD} \pm 17.02$ years, range $4-87$ years). Mean hospital stay was 3.66 days ( $\mathrm{SD} \pm 4.46$ days, range-1-21 days). Data were collected daily for all the admitted patients on previous day fulfilling the inclusion criteria. The Proforma was easy to comprehend and it was easy to fill.

Conclusion: We found that a well-designed Proforma based under supervision data collection in a relatively low volume trauma 
center. We found that a well-designed Proforma based under supervision data collection in a relatively low volume trauma center and at regular intervals can be costeffective which can be managed by personnel with basic training.

Key words: Traumatic brain injury, trauma registry, injury

\section{Introduction}

A registry is defined as a systematic collection of a clearly defined set of health and demographic related data for patients with specific health characteristics which are held in a database for a predefined purpose. (1) The role of databases is being increasingly recognized for the improvement of trauma care in healthcare environment. (2) Thus it is becoming more and more important that the hospitals who involve in the management of injured patients should have some mechanism of trauma data management. (3) Many instruments have been developed in Europe and North America but these have limited value elsewhere. (4-8) The aim of present article is to share our experiences and lessons learned from a pilot study which was conducted to collect data to serve as a model in establishing a multi-center registry on traumatic brain injury patients.

\section{Material and methods}

The present study was conducted from December 2013 to June 2014 in the Department of Neurosurgery and Department of Accident and Emergency Medicine of the Narayana Medical College and Hospital $(\mathrm{NMCH})$ in Nellore, India. NMCH is a $1200-$ bed tertiary care center, with a training program in Emergency Medicine and has 24hours facilities to manage traumatic brain injury cases with a team comprising of Emergency physicians and residents from anesthesia and neurosurgery. All patients with the diagnosis of traumatic brain injury (as per the criteria laid by International Classification of Disease injury codes ICD 10) presenting to the Departments of Neurosurgery and Emergency Medicine were included in this study. The data were collected from patients medical records; doctors' and nurses' notes records which included laboratory, radiology, and operative findings. The medical records of traumatic brain injury patients were reviewed by the treating physician and the data were obtained by a research assistant who was trained in abstracting data from medical records and was familiar with ICD-10 injury codes, (9) AIS and injury severity scoring. (10) Variables were identified as per the international norms and the data points were selected which included demographic details, pre-hospital characteristics, clinical details in emergency room, injury details, course during hospital stay, treatment and disposition. (1113) The data were categorized into master data, data related to pre-hospital events including pre-hospital care, data related to emergency room care offered in the emergency department, data related to hospital stay and patient course, outcome and follow up. (14) This pilot study protocol was approved by the Institutional Ethics Review Committee. 
DOI: 10.2478/romneu-2014-0042

\section{Statistical analysis}

Data were presented as the mean and standard deviation for continuous variables and as a percentage for categorical variables. Statistics were calculated using PSPP Statistical Software. (15)

\section{Results}

A total of 231 patients were admitted with the diagnosis of traumatic brain injury. There were $186(79.1 \%)$ male and 48 (20.5\%) female patients. Mean age of the patients was 37.19 years ( $\mathrm{SD} \pm 17.02$ years, range 4-87 years). Mean hospital stay was 3.66 days $(\mathrm{SD} \pm 4.46$ days, range-1-21 days). Most of the patient made good recovery $(82.9 \%)$ and were discharged to home (Table 1). The Proforma was easy to comprehend and it was easy to fill. Data were collected daily for all the admitted patients on previous day fulfilling the inclusion criteria.

\section{TABLE 1}

Example summary of Glasgow outcome scale at discharge and discharge destination from hospital

\begin{tabular}{|l|l|}
\hline \multicolumn{2}{|l|}{ Glasgow outcome scale at discharge } \\
\hline Death & $6(2.6 \%)$ \\
\hline Good Recovery & $194(82.9 \%)$ \\
\hline Moderate Disability & $26(11.1 \%)$ \\
\hline Severe Disability & $8(3.4 \%)$ \\
\hline Discharge destination from hospital \\
\hline Home & $196(83.7 \%)$ \\
\hline Other hospital & $33(14.1 \%)$ \\
\hline Plastic surgery & $1(0.4 \%)$ \\
\hline
\end{tabular}

\section{Discussion}

Development of trauma data registry particularly multicenter data registry needs a well-planned, systematic and step-wise approach. $(13,16-19)$ The approach needs to be comprehensive but with a short proforma, well defined inclusion and exclusion criteria, user friendly electronic database (which facilitate multi-center data collection), deployment of data entry personnel's and finally team to perform data analysis and data reporting. $(13,19)$ Before we started the whole process we discussed the factors and obstacles which are faced when conducting research in developing countries have already been discussed in the literature. $(3,20)$ It was recognized that there may not be any appreciation, there will be hardships in securing funds and it will be difficult to hire good data entry assistants. (19) However, our team took this as a challenge and decided to overcome all the hurdles and we could complete the first stage successfully.

\section{Requirements}

The successful registry depends on good patient records, documentation of all relevant information, and availability of trained personal, adequate funding and institutional support. (3, 19, 21-27) A secure source of funding, a well-defined patient population, a minimum data set, adequate staffing and training, and a means to estimate the completeness and accuracy of case reporting remain critical operational imperatives. (28)

\section{Data collection}

It has been recognized that successful establishment of registry depend on a concise 
data entry form, a user-friendly secure and accessible web-based database system. (19) The design of a trauma database is correctly identify the defined population $(3,29,30)$ and to overcome this we used ICD (10) as the standard to identify the TBI cases. One the cases are identified the next step is to design a valid, reliable and efficient data set to collect required information. (21) Standardized Proforma not only can act as an educational tool for doctors not to miss any injuries but it also can help in improved medical documentation of TBI patients. (31) Careful selection and definition of each data point is essential (21) and it is important to understand that too little data will be of limited value and too much data will be time-consuming and expensive to collect. (19)

\section{Future}

A well-designed database can be used to pool multi-center trauma data for epidemiologic reports, to compare effectiveness of care among centers and to evaluate the performance improvement indicators. (3) Commercial available data collection programs are expensive which needs training, updates and maintenance which make these commercial products inaccessible for many low and middle income countries. (21) It has created a need to locally develop electronic trauma registry software which can be used in our hospital settings. (23, $24,32)$ It is of utmost importance to understand the step to develop such a data collection system which needs a suitable and concise data entry form, a database and secure online electronic form, well trained personals to extract and enter data and most importantly personals to analyze and interpret data. (19)

\section{Limitations}

The present pilot study was conducted at a single tertiary-care teaching institution and our study circumstances may not reflect the exact situation in many of the hospitals of our country (lack of adequate facilities to handle patients with TBI). It has been learned that a public health approach in the design of trauma registries adds a level of completeness to the research and a staged approach is mandatory to refine data form and to reduce the total number of data elements. (19) In agreement of the literature the current hospital-based TBI registry is not representative of all injuries in the population as we did not take into account those patients who did not survive to reach our hospital, did not seek hospital treatment for minor injuries or were treated elsewhere. (28)

\section{Conclusions}

We found that a well-designed Proforma based under supervision data collection in a relatively low volume trauma center and at regular intervals can be cost-effective which can be managed by personnel with basic training. We believe that the information collected will help to better understand the epidemiology of traumatic brain injury in developing countries and will help in injury control, research, education, acute care, and resource allocation. (33) We also believe that the present study is a beginning to fulfill the existing gap for data collection in the field of traumatic brain injury in developing countries. In near future we are in process to 
DOI: 10.2478/romneu-2014-0042

convert the paper based data collection form into an electronic data base and interfaces to these databases. After successful completion of first pilot phase we are planning to convert the paper based proforma into electronic database to facilitate easy data entry and data retrieval.

\section{Correspondence}

Dr. Amit Agrawal

Professor of Neurosurgery

Department of Neurosurgery

Narayana Medical College Hospital

Chinthareddypalem

Nellore-524003

Andhra Pradesh (India)

Email-dramitagrawal@gmail.com

dramit_in@yahoo.com

Mobile- +91-8096410032

\section{References}

1.Solomon DJ, Henry RC, Hogan JG, Van Amburg GH, Taylor J. Evaluation and implementation of public health registries. Public health reports (Washington, DC: 1974) 1991;106:142-150.

2. Spott MA. Basic protection of trauma registry information. Journal of trauma nursing: the official journal of the Society of Trauma Nurses 2000;7:16-18.

3. Nwomeh BC, Lowell W, Kable R, Haley K, Ameh EA. History and development of trauma registry: lessons from developed to developing countries. World journal of emergency surgery: WJES 2006;1:32.

4. Gabbe BJ, Cameron PA, Wolfe R. TRISS: does it get better than this? Academic emergency medicine: official journal of the Society for Academic Emergency Medicine 2004;11:181-186.

5.Zafar H, Rehmani R, Raja AJ, Ali A, Ahmed M. Registry based trauma outcome: perspective of a developing country. Emergency medicine journal: EMJ 2002;19:391394.

6. Podang J, Singhasivanon P, Podhipak A, Santikarn C, Sarol JN, Ancheta CA. Primary verification: is the TRISS appropriate for Thailand? The Southeast Asian journal of tropical medicine and public health 2004;35:188-194.
7. Onwudike M, Olaloye OA, Oni OO. Teaching hospital perspective of the quality of trauma care in Lagos, Nigeria. World journal of surgery 2001;25:112-115.

8. Talwar S, Jain S, Porwal R, Laddha BL, Prasad P. Trauma scoring in a developing country. Singapore medical journal 1999;40:386-388.

9.ICD-10 Version:2010 [online]. Available at:

http://apps.who.int/classifications/icd10/browse/2010/e n.

10. Greenspan L, McLellan BA, Greig H. Abbreviated Injury Scale and Injury Severity Score: a scoring chart. The Journal of Trauma 1985;25:60-64.

11. WHO | Injury surveillance guidelines [online]. Available at:

http://www.who.int/violence_injury_prevention/publica tions/surveillance/surveillance_guidelines/en/.

12. TBI Standards - NINDS Common Data Elements [online]. Available at:

http://www.commondataelements.ninds.nih.gov/TBI.as px\#tab=Data_Standards.

13. Morris SC, Manice N, Nelp T, Tenzin T. Establishing a trauma registry in Bhutan: needs and process. SpringerPlus 2013;2:231.

14. Burkhardt M, Nienaber U, Holstein JH, et al. Trauma registry record linkage: methodological approach to benefit from complementary data using the example of the German Pelvic Injury Register and the TraumaRegister $\mathrm{DGU}((\mathrm{R}))$. BMC medical research methodology 2013;13:30.

15. PSPP - GNU Project - Free Software Foundation [online]. Available at:

http://www.gnu.org/software/pspp/.

16. Agrawal A. Injury surveillance or trauma registry: Need of hour and time to start. The Indian Journal of Neurotrauma 2011;8:37-39.

17. Agrawal A. A critical appraisal of neurotrauma and neurocritical care perspectives of traumatic brain injuries in Indian scenario. The Indian Journal of Neurotrauma 2013;10:38-42.

18. Joshi A, Agarwal A, Pal R, et al. The 2014 Academic College of Emergency Experts in India's INDO-US Joint Working Group (JWG) White Paper on "Developing Trauma Sciences and Injury Care in India". International Journal of Critical Illness and Injury Science 2014;4.

19. Shaban S, Eid HO, Barka E, Abu-Zidan FM. Towards a national trauma registry for the United Arab Emirates. BMC research notes 2010;3:187.

20. Abu-Zidan FM, Rizk DEE. Research in developing countries: problems and solutions. International 
urogynecology journal and pelvic floor dysfunction 2005; 16:174-175.

21. Rutledge R. The goals, development, and use of trauma registries and trauma data sources in decision making in injury. The Surgical clinics of North America 1995;75:305-326.

22. Moore L, Clark DE. The value of trauma registries. Injury 2008;39:686-695.

23. Mehmood A, Razzak JA. Trauma registry--needs and challenges in developing countries. JPMA The Journal of the Pakistan Medical Association 2009;59:807-808.

24. Schuurman N, Cinnamon J, Matzopoulos R, Fawcett V, Nicol A, Hameed SM. Collecting injury surveillance data in low- and middle-income countries: the Cape Town Trauma Registry pilot. Global public health 2011;6:874-889.

25. Cameron PA, Finch CF, Gabbe BJ, Collins LJ, Smith $\mathrm{KL}, \mathrm{McNeil}$ JJ. Developing Australia's first statewide trauma registry: what are the lessons? ANZ journal of surgery 2004;74:424-428.

26. Agrawal A, Galwankar S, Kapil V, et al. Epidemiology and clinical characteristics of traumatic brain injuries in a rural setting in Maharashtra, India. 2007-2009. International Journal of Critical Illness and Injury Science 2012;2:167-171.

27. Agrawal A, Kakani A, Baisakhiya N, Galwankar S, Dwivedi S, Pal R. Developing traumatic brain injury data bank: Prospective study to understand the pattern of documentation and presentation. The Indian Journal of Neurotrauma 2012;9:87-92.

28. Pollock DA, McClain PW. Trauma registries. Current status and future prospects. JAMA: the journal of the American Medical Association 1989;262:2280-2283.

29. Bergeron E, Lavoie A, Moore L, Bamvita J-M, Ratte S, Clas D. Paying the price of excluding patients from a trauma registry. The Journal of trauma 2006;60:300-304. 30. Mann NC, Guice K, Cassidy L, Wright D, Koury J. Are statewide trauma registries comparable? Reaching for a national trauma dataset. Acad Emerg Med 2006;13:946953.

31.Wallace SA, Gullan RW, Byrne PO, Bennett J, PerezAvila CA. Use of a pro forma for head injuries in the accident and emergency department--the way forward. J Accid Emerg Med 1994;11:33-42.

32. Schultz CR, Ford HR, Cassidy LD, et al. Development of a hospital-based trauma registry in Haiti: an approach for improving injury surveillance in developing and resource-poor settings. The Journal of trauma 2007;63:1143-1154.

33. American College of Surgeons: Trauma Programs: NTDB [online]. Available at: http://www.facs.org/trauma/ntdb/. 